\title{
LOS COMIENZOS DEL RENACIMIENTO MEDIEVAL: SAN SEVERINO BOECIO Y EL TRATADO DE INSTITUTIONE MUSICA
}

\author{
THE BEGINNINGS OF MEDIEVAL RENAISSANCE: \\ ST. SEVERINUS BÖ̈THIUS AND THE TREATISE $D E$ \\ INSTITUTIONE MUSICA
}

Lic. Emiliano Turchetta

\section{Resumen}

El presente trabajo se basa en las afirmaciones enunciadas por el dominico Guillermo Fraile respecto de la cultura de la Edad Media, las que me permiten abordar la figura de San Severino Boecio en el campo de la música a partir de la lectura de su tratado De institutione musica.

Palabras clave: Edad Media, San Severino Boecio, Música.

\section{Abstract}

The article presents Dominican Guillermo Fraile's statements in relation to the culture of the Middle Ages. This approach allows us to view the leading figure of San Severino Boecio in the field of music according to his De instituione musica treatise.

Key words: Middle Ages, San Severino Boecio, Music.

El presente trabajo es resultado parcial de un Proyecto de Investigación en realización que el autor está realizando en el Instituto de Investigación en Filosofía y Humanidades de la Facultad de Humanidades de la Universidad Católica de La Plata. 


\section{Introducción}

En la sección Preliminares de su Historia de la filosofía (segundo tomo), el dominico Guillermo Fraile, al referirse a los Aspectos culturales de la Edad Media, destaca dos características de la misma: a) La Conservación de la cultura clásica romana y la recuperación de la filosofía griega, y b) La Elaboración de una cultura propia.

Respecto de la primera, Fraile afirma que

toda la Edad Media, hasta el Renacimiento inclusive, es un largo proceso de conservación, recuperación, reincorporación y asimilación de los valores culturales, jurídicos, literarios, artísticos y filosóficos heredados de Grecia y Roma. [...]Toda la Edad Media es un continuo renacimiento, prolongado durante mil años, con manifestaciones más concretas en algunos casos particulares $y$ cuyas etapas van marcadas por la recuperación de las obras de la antigüedad. [...] Es de notar que esta recuperación se realiza dentro de un espíritu nuevo, que distingue profundamene a la Edad Media de la Antigüedad. Es el hecho del cristianismo, hondamente arraigado en Occidente después de su triunfo sobre la religión pagana (Fraile, 1986, pp. 12, 13 y 20).

En este contexto he querido presentar la figura de San Severino Boecio y el análisis de algunos aspectos de su tratado De institutione musica.
He estructurado este artículo en dos partes. La primera de ellas se refiere al cristianismo y la cultura greco-romana en el campo específico de la música, al estado de la cultura greco-romana cristiana durante el reinado de Teodorico, y a la vida de Boecio. La segunda desarrolla algunos aspectos del tratado referido.

\section{I}

\section{La cultura cristiana y la herencia greco-romana}

El problema de las relaciones con la cultura greco-romana se presentará al cristianismo bajo dos aspectos. Uno fácil, que será el de la incorporación de las artes liberales, tal como se enseñaban en las esuelas del Imperio Romano; y otro más difícil, que será el de la incorporación de la filosofía (Fraile, 1986, p. 6).

La música, una de las artes liberales, tuvo un amplio desarrollo en la antigua Grecia desde el siglo VII a.C. Obras como División del Canon, atribuida a Euclides o La armonía de Aristóxeno, ambas del siglo $\mathrm{V}$ a.C., fueron constituyendo un acervo que da cuenta de las contribuciones realizadas, fundamentalmente, en el campo de la teoría musical.

Desde el inicio de la predicación cristiana en Grecia y en las regiones que estaban bajo su influjo cultural, los creyentes tuvieron que considerar qué debían hacer, 


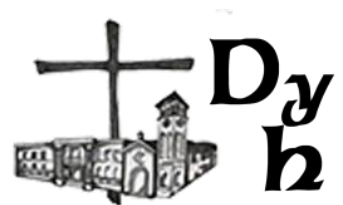

entre otras cosas, con el patrimonio musical del pasado y de la cultura pagana contemporánea (los últimos tratados de escritores paganos griegos fueron del siglo IV). Como señala el autor citado en el epígrafe, tratándose de las artes liberales, no fue difícil incorporarlas a la vida cristiana. La fe podía explicar el sentido final de todos los estudios sobre la música y también el de la música misma. La perfección y la armonía que se advertían en las leyes que regulan y conforman los sonidos podían considerarse un reflejo de la perfección y la armonía de Dios, quien había creado el sonido que hacía posible la música, con la cual, a su vez, el creyente podía alabarlo.

Como testimonio de este proceso de conversión, encontramos el Himno de Oxirrinco. Este Himno es uno de los quince ejemplos de escritura musical griega que han llegado hasta nosotros y su composición se sitúa a finales del Siglo III. En este caso, la música (el modo hipolidio), y también la poesía griega (metro anapéstico), fueron utilizadas para cantar la alabanza de la Santísima Trinidad:

...Que se haga el silencio

Que las estrellas luminosas dejen de brillar,

Que los vientos (?) y todos los ríos ruidosos dormiten;

Y con el himno al Padre, al Hijo y al Espíritu Santo,

Que todos los poderes añadan "Amén", "Amén",

Imperio, alabanza siempre $y$ gloria a Dios,
El único bienhechor, Amén, Amén ${ }^{1}$.

\section{La cultura greco-romana cristiana en el reinado de Teodorico (493-526)}

En esa larga serie de siglos [la Ilamada Edad Media], después de la invasión de los bárbaros, late una preocupación dominante, que es la de la conservación y recuperación de la herencia cultural greco-romana (Fraile, 1986, p. 3).

El Imperio Romano de Occidente terminó de existir el 4 de septiembre del año 476, con la destitución del último emperador, Rómulo Augústulo. ¿Cómo actuaron los bárbaros que se establecieron en los territorios que lo habían constituido frente a la cultura grecoromana cristiana que encontraron? El P. Alfredo Sáenz señala dos formas:

La primera, la más radical, consistía en destruir, lisa y llanamente, todo lo romano [...] Entre los pueblos invasores sólo uno intentó sistemáticamente esta experiencia, los vándalos [...]" (Sáenz, 2009, p. 91).

Por su parte, la segunda buscaba la fusión de los grandes valores de la romanidad con los aportes de los bárbaros, bajo la conducción de los jefes germanos que habían

\footnotetext{
${ }^{1}$ El Himno fue descubierto en 1918 en la ciudad egipcia de Oxirrinco. La traducción del texto fue tomada del sitio www.es.wikipedia.org, en la dirección https://es.wikipedia.org/wiki/Himno_de_Oxir rinco.
} 


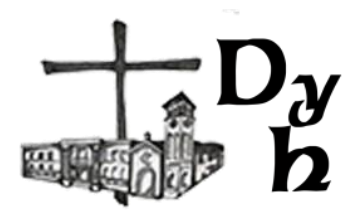

reemplazado a las autoridades imperiales, mostrándose la mayor consideración posible [...], en busca de una síntesis entre ambos elementos (Sáenz, 2009, pp. 93-94).

Una variante de la segunda modalidad fue la que llevó a cabo el rey ostrogodo Teodorico.

Teodorico, nacido hacia el año 454, fue enviado a vivir a Constantinopla en el año 463, como garantía de fidelidad de los acuerdos realizados entre su nación y el Imperio Bizantino. Durante el tiempo que permaneció en Constantinopla (463-473), pudo conocer directamente la cultura greco-romana cristiana y admirar su valor, como quedó de manifiesto desde el año 493, cuando se convirtió en rey de Italia.

En su obra La vie de Cassiodore, chancelier et premier ministre de Theodoric le grand et de plusiers autres Rois d'ltalie: ensuite Abbé de Viviers (1694), una de las más importantes que se han escrito sobre este tema, Denis de SainteMarthe ${ }^{2}$ describe exhaustivamente la actividad de recuperación llevada a cabo por el rey ostrogodo. Cito dos breves fragmentos, a modo de síntesis.

[Teodorico] unió a su gran celo por la justicia y por el buen orden, el amor por las letras, y las

\footnotetext{
${ }^{2}$ Denis de Sainte-Marthe (Paris, 1650-1725), monje benedictino de la Congregación de San Mauro. Elegido superior general de la misma en 1720. Autor de numerosas e importantes obras de teología e historia eclesiástica.
}

personas que sobresalían en las ciencias (de Sainte-Marthe, 1694, p. 67).

Sería una tarea demasiado grande querer referir aquí todo lo que Teodorico hizo en favor de las artes, porque se las vio revivir a todas, o volver a florecer bajo su reino (de Sainte-Marthe, 1694, p. 70).

La variante que encontramos en el proceder de Teodorico respecto de la segunda modalidad es la de haber buscado una convivencia cordial entre ostrogodos y romanos y sus diferentes culturas, pero sin que hubiese una asimilación entre ambas: "A los romanos las obras de paz, a los godos el cuidado de protegerlos por las armas" (citado en Sáenz, 2009, p. 96).

Esta situación también se suscitó en el ámbito religioso. Los ostrogodos eran arrianos ${ }^{3}$, en un reino de población católica ${ }^{4}$.

\footnotetext{
3 Herejía que toma su nombre de Arrio. Arrio (250 o 256- 336) comenzó formando parte de la Escuela Teológica de Antioquía pero hacia el 318 sus ideas sobre la divinidad del Señor lo llevaron a alejarse de la verdad. La doctrina arriana postuló que: "1) El Verbo comenzó a existir [...]; 2) El Verbo no es engendrado de la sustancia del Padre; ha sido sacado de la nada, por la voluntad del Padre, en orden a que le sirviera de instrumento para crear el mundo; 3) Por tanto, el Verbo no es de la misma naturaleza que el Padre [...]; 4) Habiendo sido creado, su voluntad es capaz tanto del mal como del bien, no es inmutable ni impecable" (Sáenz, 2005). El Concilio de Nicea, en 325 , se ocupó del arrianismo, demostrando y condenando su error. Hacia el 256 el arrianismo comenzó a dividirse y en 381 fue condenado nuevamente en el Concilio de
} 
Pero el equilibrio no pudo lograrse. Los problemas civiles entre godos y greco-romanos se fueron suscitando y se acentuaron hacia el final del reinado de Teodorico. Tampoco faltó la persecución de los católicos, como veremos más adelante.

\section{Severino Boecio}

En Pavía, en Lombardía, recuerdo de San Severino Boecio, mártir, que, ilustre por la doctrina y los escritos, encerrado en la cárcel escribió La consolación de la filosofía, permaneciendo fiel a Dios hasta la muerte que le fue causada por el rey Teodorico (Martirologio Romano del día 23 de octubre).

\subsection{Los primeros años (ca. 480- 498)}

Anicio Manlio Torquato Severino Boecio nació hacia el año 480; algunas fuentes sitúan su

Constantinopla. Subsistió, cada vez más aislado, en los pueblos bárbaros, hasta su desaparición en el siglo VII.

${ }^{4}$ Denis de Sainte-Marthe nos informa sobre Teodorico y su relación con el catolicismo durante los primeros tiempos de su reinado. "Bien lejos de forzar sus súbditos a abjurar la fe Católica, para hacerlos arrianos, no podía tolerar el cambio de religión, como lo demostró en el caso de uno de sus cortesanos, que había abrazado la herejía, persuadiéndose de hacer una cosa agradable a este Príncipe. Si tu no has conservado la fe en tu Dios, le dijo Teodorico, ¿cómo la conservarás a tu rey, que es un hombre? Y, enseguida, le hizo cortar la cabeza" (de Sainte-Marthe, 1694, p. 58). nacimiento entre los años 475 y 477. Era descendiente de una antigua y noble familia, la gens Manlia, y estaba emparentado, por parte de madre, con la gens Anicia, cuyo nombre ya aparecía en el Siglo IV a.C., y de la que formaron parte tres papas (San Félix III, San Agapito I y San Gregorio I Magno), el padre del monacato occidental, San Benito, y algunos senadores y cónsules.

Habiendo perdido el padre aproximadamente en el año 490, Quinto Aurelio Memio Símaco, romano de la prestigiosa gens Symmachi, hombre de una gran fe y de una vasta cultura, tomó a su cargo la educación del joven.

Boecio, entonces, por parte de su familia y por parte de Quinto Símaco, recibió una óptima formación.

\subsection{El Papado de San Símaco y la visita de Teodorico a Roma (498- 500)}

El 22 de noviembre del año 498, el Archidiácono Símaco fue elegido Papa. El mismo día, el Senador Festo y un grupo de romanos cismáticos, eligieron al antipapa Lorenzo. Teodorico, que se encontraba en Ravena, y Quinto Símaco (desde el 495 suegro de Boecio por el matrimonio con su hija Rusticiana), se manifestaron a favor del Papa. El 1 de marzo del año 499, en un Concilio celebrado en Roma, Lorenzo reconoció la legitimidad de Símaco y depuso su actitud. 


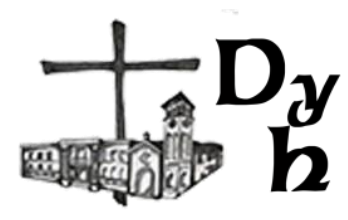

Teodorico, que desde su llegada a Italia no había ido a Roma, pensó que el fin del conflicto que se había suscitado era una buena ocasión para visitar la ciudad, a donde llegó en el año 500.

El rey entró en Roma en medio de las aclamaciones de los romanos, que se consolaron de la pérdida de sus Emperadores, viendo este Príncipe [...] vestido a la Romana, seguido por una Corte magnífica $y$ por un numeroso cortejo de senadores, volver a trazar la imagen del antiguo esplendor del Imperio. [...] Con el fin de concluir el gran problema, que había sido el motivo principal de su viaje, se convocó un Concilio, en el cual el Papa Símaco hizo conocer su inocencia (de Sainte-Marthe, 1694 , p. 63).

Durante los seis meses que Teodorico estuvo en Roma, se encontró, posiblemente, con Quinto Símaco y con Boecio, quien, en la misma época, había comenzado una de las tareas que ocuparon toda su vida, el comentario de obras de la antigüedad griega.

A Boecio no podía ocultársele la circunstancia que, a consecuencia de las complicaciones sucedidas en el Siglo V, la situación cultural de Occidente había decaído. ¿Qué pensaría entonces de los discursos hechos "con mucha elocuencia" por Teodorico? (de Sainte-Marthe, 1694, p. 63)

¿Teodorico podía ser quien diera comienzo a una tarea de reconstrucción, de renacimiento? La respuesta a esta pregunta podría ser afirmativa. El mismo rey lo había manifestado con una obra simbólica:

Con el fin de dar señales de su magnificencia y de su amor por la romanidad, [...] asignó dinero considerable para ser empleado en la reparación de las murallas de la ciudad (de Sainte-Marthe, 1694 , p. 63).

Sin embargo, quedaba latente un grave problema: ¿Cómo se comportaría Teodorico ante la cultura clásica, iluminada y purificada por la verdad católica, tratándose de un arriano? Podemos suscribir lo dicho por el P. Sáenz: "En lo que toca a la diferencia religiosa, podía esperarse que con el tiempo el asunto se arreglaría" (Sáenz, 2009, pp. 98).

\subsection{Los años de la tarea de recuperación (500-524)}

En los años que siguieron a la visita de Teodorico a Roma, ca. 502507, Boecio comenzó a escribir los tratados que se ocuparon de lo que él mismo llamó quadrivium ${ }^{5}$ : el estudio de la matemática dividida en cuatro partes, la aritmética, la geometría, la música y la astronomía ${ }^{6}$. Con estos escritos, Boecio intentaba recuperar mucho de la antigüedad griega: los estudios

5 El nombre de Artes liberales será reemplazado por el de Trivium y Quadrivium en la Edad Media.

${ }^{6}$ Dos de ellos han llegado hasta nosotros, el De institutione arithmetica y el De institutione musica. 
realizados por Nicomaco de Gerasa y por Tolomeo, entre otros. De institutione musica, estaba destinado a convertirse en uno de los tratados más importantes de la Edad Media y de toda la historia de la música. Me ocuparé de él más adelante, pero quisiera detenerme en un episodio que pone en evidencia la consideración que adquirió Boecio en materia musical luego de su escritura.

Hacia el día de Navidad del 496, Teodorico se casó con Audofleda, hermana menor de Clodoveo (Clovis) I, el rey de los francos. Clodoveo, que tal vez por referencias de los integrantes de la embajada que acompañó a su hermana a Ravena, tenía conocimiento de la música que se hacía en la corte de Teodorico, le pidió a su cuñado que le enviara un ejecutante de arpa. Teodorico se dirigió a Boecio a través de una carta que le redactó Casiodoro ${ }^{7}$, su questor sacri palatii, y en la que expresó:

He prometido satisfacer el pedido que me hace el rey de los Francos solo porque conozco toda tu habilidad en la música, y que he contado contigo, que has llegado por tus estudios a las cumbres más difíciles de esta ciencia, para designarme el

\footnotetext{
${ }^{7}$ Magno Aurelio Casiodoro (ca. 485-ca.580). Amigo y pariente de Boecio, con quien coincidió en su tarea de recuperar el patrimonio cultural de la antigüedad grecoromana a través de sus escritos. Hacia mediados del Siglo VI fundó el monasterio de Vivarium, en el que él y los demás monjes se dedicaron a copiar libros, tarea ampliamente desarrollada en la Edad Media.
}

hombre más hábil en ese campo [...] Elige entonces el mejor ejecutante de arpa de nuestro tiempo y que él sea como otro Orfeo, que dome por la suavidad de sus notas la dureza de los corazones de los Gentiles. Tantos serán los agradecimientos que nos enviará, tantos, por una justa compensación, te dirigiré, por haber sabido a la vez obedecer a mis órdenes $y$ distinguirte tu mismo (Casiodoro, 1865, 570$573)^{8}$.

Boecio encontró, seguramente, al ejecutante de arpa porque Teodorico, a su vez, le escribió a Clodoveo: "Te envío el arpista que me habías solicitado. Deleitará tus oídos cantando tu gloria, conjuntamente con las manos y la voz." (Casiodoro, 1865, 573-574).

A los tratados mencionados siguieron traducciones del griego, comentarios de obras de Aristóteles y Cicerón y tratados filosóficos. Desde el 512 hasta el 520 escribió cinco tratados teológicos: dos de ellos son De Trinitate y De fide Catholica. Hacia el 515, Boecio anunció que pensaba traducir y comentar todas las obras de Platón y las de Aristóteles.

Además de sus actividades filosóficas y de restauración renacentista, Boecio se desempeñó como cónsul durante dos años, a partir del 1 de enero del 510 (el cónsul también era el presidente del

\footnotetext{
${ }^{8}$ Se trata de la tercera carta dirigida a Boecio que aparecen en el Variarum.

9 Es la carta número 41 del Libro II del Variarum.
} 


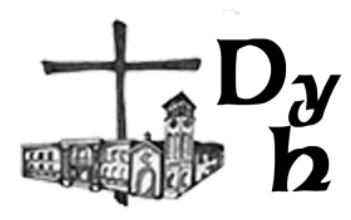

Senado y concluida su función, continuaba formando parte del mismo). En el mes de agosto de $522^{10}$, Teodorico llamó a Boecio para que ejerciera como magister officiorum $^{11}$ de su Corte, cargo donde permaneció hasta agosto de 523.

\section{¿Qué podríamos pensar respecto de la totalidad de la producción de Boecio? Una carta del propio Teodorico puede servir para ofrecernos algunas conclusiones:}

Por vuestros trabajos, la lengua latina se ha enriquecido con la música de Pitágoras, la astronomía de Ptolomeo, la artimética de Nicómaco, la geometría de Euclides, la filosofia de Platón, la lógica de Aristóteles y la mecánica del siciliano Arquímedes. $Y$ todas las demás artes $y$ disciplinas que pronunciaron singularmente muchos hombres en Grecia, Roma las recibió por un autor de su lengua materna (Casiodoro, 1865, pp. 539-541) ${ }^{12}$.

${ }^{10}$ Ese mismo año, los hijos de Boecio fueron nombrados cónsules.

${ }^{11}$ El magister officiorum tenía a su cargo varias dependencias y era uno de los funcionarios más importantes de la corte. El cargo existía desde tiempos del Bajo Imperio Romano.

${ }^{12}$ Es la carta número 45 del libro I, del año 507 , en la que se le pide a Boecio que construya un reloj "acuático y solar" que le ha solicitado el rey de los burgundios, Gundebaldo. Se trata de la segunda carta dirigida a Boecio de las que aparecen en el Variarum.

\subsection{Los años finales (524-526)}

En el año 524, a partir de una acusación falsa, Teodorico puso a Boecio en prisión, en la ciudad de Pavía, donde escribió la obra que lo ho hizo más célebre : De consolatione philosophiae, donde también se ocupó de la música.

En el 525 Teodorico firmó la sentencia de muerte contra Boecio, que fue ejecutada al poco tiempo. La condena de Boecio se desarrolló en un clima de creciente desconfianza y persecución. Teodorico imaginó que los católicos se preparaban para pedir a Justino I, Emperador de Oriente, que también era católico, que lo atacara y lo destituyera.

Al mismo tiempo, Quinto Símaco fue llamado a Ravena, y bajo falsas acusaciones, condenado y ejecutado. El Papa San Juan I, maltratado y encarcelado por orden del rey ostrogodo, murió poco después, el 18 de mayo de 526; se lo recuerda litúrgicamente como San Juan I, papa y mártir. Los remordimientos que le causaron estos crímenes entristecieron profundamente a Teodorico, que enfermó y murió el 30 de agosto de ese mismo año.

El renacimiento que había protagonizado Boecio parecía concluido, pero iba a continuar inmediatamente, a través de Casiodoro, en los scriptoria de los monasterios. 


\section{II}

\section{El tratado De institutione musica $^{13}$}

De modo que a partir de todas estas cosas se muestra, de forma transparente y sin lugar a dudas, que con nosotros la música está por naturaleza conjuntada de tal manera que, ni si quiera aunque queramos, podemos estar privados de ella (Boecio, 2009, $\mathrm{p}$. 75).

\subsection{Las fuentes de la obra}

Como precedentemente dijimos, Boecio anunció, hacia el año 515, su proyecto de traducir y comentar todas las obras de Platón y de Aristóteles (cf. Boecio, 1891, p. 433), proyecto que no pudo completar. Su intención era continuar, luego, con la búsqueda de una síntesis que armonizara las opiniones de ambos.

Una situación similar podemos encontrar en su tratado sobre música. Nicómaco de Gerasa, filósofo y matemático neopitagórico, Euclides, matemático y geómetra, y Claudio Ptolomeo, astrónomo y matemático, constituyeron las fuentes griegas de su obra. La presencia de Nicómaco y de

${ }^{13}$ Para el presente trabajo contamos con la siguiente edición: Boecio, Sobre el fundamento de la música, Cinco libros, Introducción, Traducción y notas de Jesús Luque, Francisco Fuentes, Carlos López, Pedro R. Díaz y Mariano Madrid, Madrid, Editorial Gredos, 2009.
Ptolomeo podrían hacer pensar en el "pitagorismo" musical de Boecio, en desmedro de la otra escuela musical griega, la de Aristóxeno. Sin embargo, en la Introducción de la edición consultada, Jesús Luque escribe que

valiéndose, por tanto, de estas fuentes, recoge Boecio lo más sustancial de la tradición musical pitagórica (Pythagoras musicus), desde las especulaciones cosmológicas a las medidas del monocordo [instrumento musical utilizado para estudios sobre los sonidos]; sin que por ello se muestre ajeno a la otra escuela harmónica, la aristoxénica, de cuyo conocimiento da muestras a lo largo de toda la obra (Luque, 2009, pp. 15-16).

Tomemos dos ejemplos: 1) El capítulo 3 del Libro $V$ se denomina "Qué es la regla armónica o cuál dijeron que es la intención de la 'armónica' los pitagóricos o bien Aristóxeno o bien Ptolomeo". 2) El capítulo 4 del Libro $V$ se denomina "En qué establecieron que consistía la gravedad y la agudeza [del sonido] bien Aristóxeno, bien los pitagóricos, bien Ptolomeo".

En el segundo de los capítulos mencionados podemos leer:

Puesto que, de hecho, todos están de acuerdo en que el sonido es una percusión del aire [Boecio busca la síntesis de las escuelas en esta definición], la diferencia entre la gravedad y la agudeza la establecían según teorías contrapuestas los que 
seguían a Aristóxeno y los pitagóricos (Boecio, 2009, p. 350).

Otra fuente de la obra la encuentra en el romano Albino, hombre político y musicólogo del Siglo IV, "a través del cual, si no directamente, [Boecio] pudo haber conocido el De musica de Arístides Quintiliano" (Luque, 2009, p. 15) ${ }^{14}$.

\subsection{La forma de la obra}

El tratado de Boecio, tal como ha llegado hasta nosotros, consta de cinco libros. Se puede pensar que era más extenso porque el autor dejó escrito un índice y en el Libro $V$ incluye más capítulos de los que aparecen escritos. La edición consulada señala que los Libros pudieran ser siete, porque en el último que integra el tratado, Boecio se ocupa del primero de los tres libros que constituyen la Harmonica de Ptolomeo y podría suponerse que tenía la intención de continuar comentando los otros dos.

El primer libro se presenta como una introducción de la obra y consta de 34 capítulos. En ellos, Boecio habla de temas diversos, por ejemplo, las clases de música (cap. 2), el sonido, el intervalo [musical] y la consonancia [de los sonidos] (cap. 8), la definición del músico (cap. 34).

\footnotetext{
${ }^{14}$ Albino era católico y a causa de unas cartas que envió al Emperador de oriente, también católico, fue acusado de traición ante Teodorico por el referendarius Cipriano, en el año 522. Fue defendido por Boecio, a quien Cipriano también acusó. Ver la sección 3.4 del presente trabajo.
}

El segundo libro consta de 31 capítulos y trata de asuntos esencialmente técnicos; Boecio se refiere a la aritmética (la ciencia que estudia los números). La aritmética es la primera de las ciencias del quadrivium y brinda los principios que luego se aplican al sonido.

El tercer libro consta de 16 capítulos y tiene características similares al precedente.

El cuarto libro consta de 18 capítulos; en nueve de ellos, Boecio, emplea los principios aritméticos que ha detallado en las posibles divisiones de la cuerda del monocordio. Luego se refiere a las clases de consonancias.

El quinto libro consta de 30 capítulos, pero se conservan 19. En ellos trata, por ejemplo, de los intervalos musicales (la distancia entre una nota y otra) y de la división del tetracordio (la serie descendente de cuatro notas sobre la que se organizaba la teoría musical de la antigua Grecia).

\subsection{Consideraciones sobre el Libro I}

En el primer capítulo del Libro, el Proemio, Boecio deja en claro que es necesario estudiar seriamente aquello que se quiere saber:

"No entraña, en efecto, trabajo alguno el que apliquemos el sentido a la percepción de las cosas sensibles; cuál es, en cambio, la naturaleza de los propios sentidos, de acuerdo con los cuales actuamos, cuál la 
propiedad de las cosas sensibles, eso no es obvio ni puede ser explicable para cualquiera, a no ser para aquel a quien guíe en su observación una investigación adecuada de la verdad. [...] Cuando alguien se vuelve a mirar un triángulo $\mathrm{o}$ un cuadrado, fácilmente reconoce lo que ve con los ojos, pero cual es la naturaleza del cuadrado o del triángulo es preciso que lo consulte a un matemático" (Boecio, 2009, pp. 59-60).

excepción.

La música no es una

Por lo cual, hay que tensar la fuerza de la mente para que eso que por naturaleza es innato pueda también ser dominado una vez aprehendido por la ciencia. Pues, así como también en la visión no les basta a los eruditos observar los colores y las formas, si no investigaren cuál es la propiedad de ellos, así no les basta a los 'músicos' deleitarse con unas cantilenas, si no se aprende también a base de qué tipo de proporción de las voces entre sí se hallan conjuntadas (Boecio, 2009, p. 75).

La importancia que Boecio concede a la música en relación con las demás ciencias de la matemática tiene su origen en una característica particular de la primera: "siendo cuatro las disciplinas de la mathesis y ocupándose, por cierto, las demás de la investigación de la verdad, la música, en realidad, no sólo está ligada a la especulación sino también a la moralidad" (Boecio, 2009, p. 61). Boecio tiene presente que una música buena puede ser buena para el alma. ¿No le escribe Teodorico respecto del arpa: "que dome por la suavidad de sus sones la dureza del corazón de los Gentiles?" (Casiodoro, 1865, pp. 573-574). La antigua teoría griega del ethos es retomada e iluminada por un escritor cristiano.

¿Qué es un músico para Boecio? La definición ocupa el Capítulo final, el 34, del Libro I, y para llegar a ella, comienza con una aclaración necesaria: "Toda arte e incluso toda disciplina tiene por naturaleza un sistema teórico más honorable que la pericia artesanal que se ejerce por mano y obra de un artesano" (Boecio, 2009, p. 148). Dios nos ha dado la posibilidad de hacer música, pero no para improvisar sin fundamentos sino para conocer sus reglas y poder dar una razón a la pericia artesanal. La nota de la edición consultada dice: "La correspondencia de este capítulo, así como algunas ideas del capítulo primero (la connaturalidad de la música a nosotros), con el tratado de San Agustín (Mús. I 4, 5-6,12) parece evidente" (Boecio, 2009, p. 148, n. 276).

La definición de músico se puede, entonces, prever: "Músico [...] es aquel que ha asimilado la ciencia del canto [de la ejecución musical] a base de razonamiento sopesado, no bajo la esclavitud de la práctica, sino bajo el mando de la especulación" (Boecio, 2009, p. 149).

Se podría pensar que el músico, para Boecio, no necesita ser ejecutante. Pero el ejecutante, para 


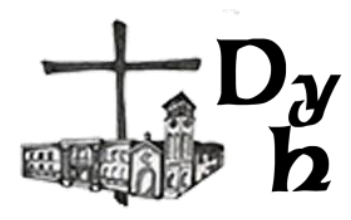

ser músico, debe saber que es la música, qué se puede descubrir en el fenómeno sonoro.

Por eso es necesario que el estudio de la música sea serio. El instrumentista puede ser músico $\mathrm{y}$ puede reflejar con absoluta y suma imperfección la perfección divina, pero debe esforzarse por hacerlo de la mejor manera posible.

\section{Bibliografía}

Boecio, S., 2009: Sobre el fundamento de la música, Cinco libros, Introducción, Traducción y notas de Jesús Luque, Francisco Fuentes, Carlos López, Pedro R. Díaz y Mariano Madrid, Madrid, Editorial Gredos.

Boecio, S., 1891: In Librum Aristotelis De Interpretatione, Editio secunda, en Boecio, S.: Opera omnia [Patrologia latina 64], J.-P. Migne editor, París, pp. 394-640: http:// patristica.net/latina/\#t064

Casiodoro, M. A., 1865: Variarum Librim duodecim, en Casiodoro, M. A.: Opera omnia, v. 1 [Patrologia latina 69], J.-P. Migne editor, París, pp. 501-880: http://patristica.net/ latina/\#t069

Fraile, G., O.P., 1986: Historia de la filosofía, Historia de la Filosofía, Tomo II (I. ${ }^{\circ}$ ) El cristianismo y la filosofía patrística. Primera escolástica, Cuarta Edición por Teófilo Urdanoz, O.P., Madrid, Biblioteca de Autores Cristianos.
Luque, J., 2009: Introducción, en Boecio, Sobre el fundamento de la música, Madrid, Editorial Gredos.

Sáenz, A., S.J., 2005: La Nave y las tempestades, Tomo I, Buenos Aires, Ediciones Gladius.

Sáenz, A., S. J., 2009: La Nave y las tempestades, Tomo 2, Buenos Aires, Ediciones Gladius.

de Sainte-Marthe, D., O.S.B., Congregación de San Mauro, 1694: La vie de Cassiodore, chancelier et premier ministre de Theodoric le grand et de plusiers autres Rois d'Italia: ensuite Abbé de Viviers, Paris, Casa Jean Baptiste Coignard. 